\title{
An integrated design method for remanufacturing process based on performance demand
}

Chao Ke ( $\nabla$ karlkc@163.com )

Wuhan University of Science and Technology

\section{Zhigang Jiang}

Wuhan University of Science and Technology

Shuo Zhu

Wuhan University of Science and Technology

\section{Yan Wang}

University of Brighton

\section{Research Article}

Keywords: Remanufacturing process, performance, BPNN, TRIZ

Posted Date: May 17th, 2021

DOl: https://doi.org/10.21203/rs.3.rs-508261/v1

License: (c) (i) This work is licensed under a Creative Commons Attribution 4.0 International License. Read Full License

Version of Record: A version of this preprint was published at The International Journal of Advanced Manufacturing Technology on September 8th, 2021. See the published version at https://doi.org/10.1007/s00170-021-07923-5. 


\title{
An integrated design method for remanufacturing process based on performance demand
}

\author{
Chao Ke ${ }^{1,2}$, Zhigang Jiang ${ }^{1,2}$, Shuo Zhu ${ }^{2,3}$, Yan Wang ${ }^{4}$ \\ 1.Hubei Key Laboratory of Mechanical Transmission and Manufacturing Engineering, Wuhan \\ University of Science \& Technology, Wuhan 430081, China \\ 2.Key Laboratory of Metallurgical Equipment and Control Technology, Wuhan University of Science \& \\ Technology, Wuhan 430081, China \\ 3.Academy of Green Manufacturing Engineering, Wuhan University of Science \& Technology, Wuhan \\ 430081, China \\ 4.Department of Computing, Engineering and Mathematics, University of Brighton, Brighton, BN2 4GJ, \\ United Kingdom, United Kingdom \\ Corresponding author: Zhigang Jiang, E-mail: jzg100@163.com
}

\begin{abstract}
Design for remanufacturing process (DFRP) plays a key role in implementing remanufacturing because it directly affects the performance recovery of the End-of-Life (EoL) product. Since the used parts have various failure forms and defects, these make it hard to rapidly generate the remanufacturing process scheme for satisfying the performance demand of the used product. Moreover, remanufacturing process parameters are prone to conflicts during the process of implementing remanufacturing, this leads to the failure of the remanufacturing process. For accurately generating remanufacturing scheme and solving the conflicts, an integrated design method for remanufacturing process based on performance demand is proposed, which can reuse the historical remanufacturing process data for generating the remanufacturing process scheme. Firstly, for accurately describing the performance demand, the Kansei Engineering (KE) and Quality Functional Development (QFD) are applied to analyze the performance demand data and map the demand to the engineering features. Then, Back Propagation Neural Network (BPNN) is applied to inversely generate the remanufacturing process scheme rapidly for satisfying the performance demand by reusing the historical remanufacturing process data. Meanwhile, Theory of Constraint (TOC) and TRIZ are used to identify the conflicts of the remanufacturing process and resolve the conflicts for optimizing the remanufacturing process scheme. Finally, DFRP of the saddle guideway is taken as an example to demonstrate the effectiveness of the proposed method, the result shows the design method can quickly and efficiently generate the remanufacturing process for the EoL guide rail.
\end{abstract}

Keywords: Remanufacturing process, performance, BPNN, TRIZ

\section{Introduction}

With increasing attention to environmental pollution and energy consumption, as well as the strict legislation of government, the disposal of End-of-Life (EoL) products (which are called the cores) has received considerable attention in the past few decades [1]. Remanufacturing is an industrial process of returning EoL products back to service in a condition that is like-new or better than new via a series of remanufacturing processes [2]. The surplus-value of used parts can be maximized through remanufacturing, and the utilization rate of resources can be improved. Hence, remanufacturing process is a vital step in implementing remanufacturing, which directly impacts the cost as well as recovery performance and efficiency for remanufacturing.

Although the remanufacturing process has huge benefits, the failure features of the used products are diverse and uncertain, which make the remanufacturing process design process very complicated and 
time-consuming, and it is also difficult to accurately restore the performance of used products to customer expectations. In addressing these problems, several researchers have made contributions to the various aspects of remanufacturing process design. For example, Jiang et al. presented a remanufacturing process selection method, in which the functional relationship between remanufacturing performance and process quality characteristics is established by using QFD and fuzzy linear regression method for obtaining the optimal solution [3]. Wang et al. proposed an optimization method to characterize fault features for remanufacturing process planning, overcoming limitations of traditional characterization methods of fault features [4]. Shakourloo proposed a multi-objective stochastic goal programming model of remanufacturing process to optimize the remanufacturing process considering profit and cost objectives, the ratio of products that should be ordered for remanufacturing process can be decided by applying the model [5]. Li et al. proposed an analytical method, where four GERT-based RPR models are proposed to mathematically represent to determine the time and probability of individual processes being taken in a remanufacturing system [6]. Kin et al. proposed a conceptual framework and methodology to aid in the selection of the reconditioning process sequence by analyzing the conditions of the core components [7]. Zhang et al. proposed an integrated model based on QFD, fuzzy linear regression, and zero-one goal programming model that provides the means for incorporating not only the relationships between decision objectives and decision variables but also the interactions between decision variables through adopting the QFD principles [8]. Cao et al. proposed a two-phase decision-making strategy, which was based on the experts' assessment and fuzzy regression theory together, uncertainty was avoided in the decision-making process and incomplete information [9].

The current research on remanufacturing process is mainly divided into three categories: remanufacturing process generation, remanufacturing process optimization, and remanufacturing process decision-making. Undoubtedly, the above researches have provided much useful knowledge for remanufacturing process, however, there is little research carrying out the design method for remanufacturing process (DFRP) from the perspective of the performance demand of the remanufactured products. The purpose of DFRP is to formulate a reasonable remanufacturing process scheme so that the used products can be processed into the remanufactured products that meet performance demand. Performance demand can be classified original performance of the product and the upgrade performance, which contains strength upgrade, hardness upgrade and accuracy upgrade, etc. In general, customers are not professional technicians, so customer demand are vague and perceptual when describing performance demand, this will extract biased design goals. Therefore, it is necessary to propose effective methods to accurately describe customer demand. Kansei Engineering (KE) aims to realize the customer's feelings and demand for product functions and design, which is defined as 'translating customer sensibility into product design domain' [10]. Hartono proposed a modified-integrated method for sustainable service design which applied Kansei Engineering to highlight the customer emotional satisfaction [11]. Jiao et al. proposed a method for Kansei knowledge extraction from the online review of the product, which can improve the design efficiency [12]. Yeh and Chen proposed a service design method that combines Kansei Engineering and data mining technology for transforming the users' subjective feelings to the design specification [13]. It can be known from the literatures that KE is an effective method to describe the emotional demand of the customer, which is helpful for designers to extract the key performance requirements of the product. Moreover, the performance demand needs to be converted into engineering features of the product, so that the designer can more accurately determine the design targets. Quality Functional Development (QFD) is a 
methodological tool designed to solve problems that aims to maintain customer demand throughout the design process, and promote communication between design participants [14]. Fang et al. proposed a new product model based on QFD for integrating the diverse customer demand into product design, which can realize the idea of customer-oriented design [15]. Sousa-Zomer et al. proposed an approach based on Quality Functional Development for translating the stakeholder' requirements into engineering metrics of the products and services [16]. Mistarihi et al. proposed a new enhanced model to improve the quality of the QFD method, which integrates customer needs and engineering features to achieve the optimal goal [17]. From the literatures mentioned above, QFD can translate the customer demand into the product engineering features, and determine the weights of each feature, this helps designers determine the design goals of the remanufacturing process. Thus, it is a feasible method to describe the performance demand and map the performance demand to the engineering features by using KE and QFD.

Performance demand is the key goal in DFPR, meanwhile, DFRP needs to consider many factors, such as damage features of the cores, process route, process route, etc. For the foregoing reasons, DFRP is time-consuming and tedious, which is hard to generate a suitable remanufacturing process scheme rapidly. To address this problem, BPNN is proposed to solve the problems for DFRP by reusing the existing remanufacturing process data. BPNN has arbitrarily complex pattern classification capabilities and excellent multi-dimensional function mapping capabilities, which has been widely used in each field. Huynh and Recycling presented a model for predicting the detect to assist shop floor operations, which apply BPNN to predict the detects at each stage of the manufacturing process [18]. Chang et al. proposed an improved BPNN method to establish the relationship between the penetration quality and the welding process parameters, which can predict the penetration quality based on the welding data [19]. Feng et al. proposed a data-driven learning algorithm to improve the prediction capacity of fatigue life by considering stochastic parameters of structures, and BPNN is used to predict the fatigue life based on the stochastic parameters database [20]. Kwon addressed an integrated performance measurement and prediction model, which applied BPNN to predict an efficiency score and target output for each decision-making unit of the railroads [21]. From the literatures mentioned above, BPNN has an excellent multi-dimensional function mapping ability which can establish the prediction model between the target goal and the influence variables. For improving the efficiency of the DFRP, BPNN is used to establish the prediction model between performance demand and remanufacturing process scheme, the performance variables are input parameters, and failure features are also used as input parameters, which can improve the prediction accuracy, besides, the remanufacturing process scheme is used as output parameters, which is expressed by serial number. The BPNN is trained with the historical remanufacturing process data, when the BPNN model reaches the set prediction error threshold, the remanufacturing process scheme can be predicted according to the performance demand. Although the BPNN model has high prediction accuracy, the unreasonable remanufacturing process scheme will still be input which is prone to occur process conflicts since the actual remanufacturing scheme is not considered. To address the process conflicts, TRIZ is proposed which is a whole set of systemized theory and method for solving invention-related problems [22], and has been used widely in various fields to solve design problems. Ho-Nien Hsieh et al. proposed a decision-making trial and evaluation laboratory-based analytic network process (DANP) and the TRIZ to the innovative design of machine tools, TRIZ provided several techniques to facilitate problem-solving [23]. BAO et al. TRIZ is applied to solve the innovation issue in the active remanufacturing design process, which improved 
the efficiency and success rate of the structural green design for active remanufacturing [24]. From the literatures mentioned above, conflict problems are solved and innovative design schemes are generated by using TRIZ. In addition, the conflicts of the remanufacturing process scheme are not easy to be detected, it is necessary to identify the conflicts from the implementation of the remanufacturing process to the realization of the remanufactured product performance. Theory of Constraints (TOC) can help designers find the key factors that affect the actual production system [25], which is an effective method to construct and analyze the problems of the production system. Besides, TOC is mainly composed of five logical diagrams, which is used to solve and correct errors in conflict problems [26], the current reality tree (CRT) is used to put forward the possible causes of the conflicts [27], and the contradiction resolution diagram (CRD) is applied to express the relationship among one target, two basic requirements and two prerequisites of the system, which can determine the relevant factors in the conflicts and find ways to resolve the conflicts [28]. Hence, TOC is an effective method to find the conflicts and determine the direction to solve the problem, TRIZ can provide innovative solutions to problems.

To improve design efficiency and solve the conflicts for DFPR, an integrated design method for remanufacturing process based on performance demand is presented in this study. In short, the main contributions of this study compose three aspects: (1) an integrated design framework for remanufacturing process based on performance demand is established, which can reuse the historical remanufacturing process data to generate remanufacturing process scheme. (2) BPNN is used to build the predictive model between the performance demand and the remanufacturing process scheme, simultaneously, the failure features of the used products are considered in the input parameters, which can improve the predictive accuracy. (3) the TOC and TRIZ theory are used to identify and resolve the conflicts of the remanufacturing process scheme, which can optimize the remanufacturing process scheme and improve the success rate of remanufacturing.

The rest paper is organized as follows. In section 2, an integrated design framework for the remanufacturing process is proposed. Section 3 analyzes the performance demand based on the KE and QFD, and establishes the prediction model based on BPNN. In section 4, the TOC and TRIZ theory are used to identify and resolve the conflicts of the remanufacturing process scheme. Then, a case study is presented to verify the feasibility of the proposed method in section 5. Finally, conclusions are given in section 6 .

\section{The implementation framework of DFPR}

The remanufacturing process is an important factor in the restoration of the used products, and determines whether the performance of the remanufactured product can be restored and exceeds the original product performance. In addition, the reasonable remanufacturing process can reduce remanufacturing costs and improve remanufacturing efficiency. Therefore, it is necessary to develop a design method for remanufacturing process which can generate a suitable remanufacturing scheme. This study proposes an integrated design method for remanufacturing process which contains remanufacturing process scheme generation and remanufacturing process scheme optimization, the process framework of DFPR is as shown in Fig.1. The first part is performance demand analysis which contains performance upgrade demand and performance restoring demand, the second part is the remanufacturing process scheme prediction based on the performance demand by using BPNN, then, 
the TOC and TRIZ theory are used to identify the conflicts of the remanufacturing process scheme and resolve the conflicts. Finally, the improved remanufacturing process schemes are feedback to the remanufacturing process scheme database.

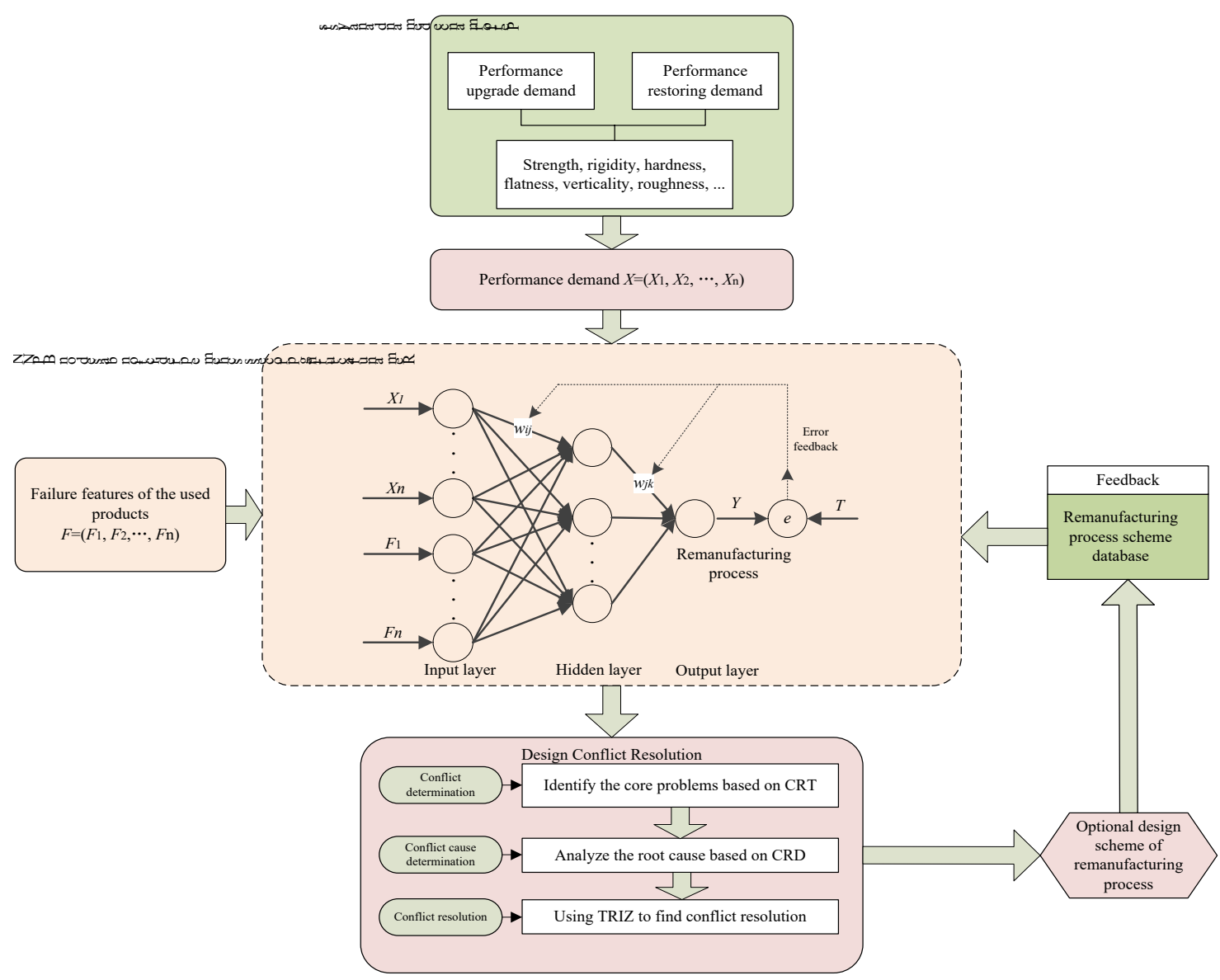

Fig.1. The framework of DFRP

\section{Remanufacturing process scheme prediction and optimization}

\subsection{Performance demand analysis}

Performance demand (PD) mainly includes performance upgrade demand and performance repair demand, the former is mainly to improve the original performance of the product, such as improving strength, hardness and flatness, the latter is mainly the demand to restore the original performance of the product. In order to standardize the expression of performance demand information, the Likert tables are used to collect demand information, which is shown in Table 1.

Table 1 The five-point Likert scale for performance demand

\begin{tabular}{|c|c|c|c|c|c|c|c|}
\hline \multirow{2}{*}{ Number } & \multirow{2}{*}{ Object } & \multirow{2}{*}{ Perceptual evaluation } & \multicolumn{5}{|c|}{ Demand intensity } \\
\hline & & & 1 & 2 & 3 & 4 & 5 \\
\hline 1 & $\begin{array}{l}\text { Guiderail } \\
\text { surface }\end{array}$ & Smooth & & & & & $\sqrt{ }$ \\
\hline 2 & $\begin{array}{l}\text { Surface } \\
\text { hardness }\end{array}$ & Hard & & & & $\sqrt{ }$ & \\
\hline 3 & $\begin{array}{c}\text { Tailstock } \\
\text { concentricity }\end{array}$ & Unanimous & & & & $\sqrt{ }$ & \\
\hline 4 & Guide rail & Smooth & & & & $\sqrt{ }$ & \\
\hline
\end{tabular}


flatness

The five-point Likert table can perceptually describe the performance demand of customers, and score the intensity of the demand, so as to more accurately describe the performance demand and tendencies. The demand intensity divides into three levels: \{strongly disagree, disagree, uncertain, agree, strongly agree $\}$, with a corresponding score is $\{1,2,3,4,5\}$. After collecting the performance demand information, QFD is used to map the performance demand to the engineering features and quantitative the engineering feature value, which can be described as Table 2. PD represents the performance demand, $w_{\mathrm{pj}}$ is the $\mathrm{j}$-th weight of the performance demand, $E_{\mathrm{k}}$ indicates the strength of the correlation between engineering features and performance demand, which is divided into four levels: \{strong, general, weak, irrelevant $\}$, with a corresponding score is $\{3,2,1,0\}$. R represents the rank of the correlation. $v_{\mathrm{p}}$ denotes the value of the performance demand, the value of the performance repair demand is the origin performance of the used product, the value of the performance upgrade demand is the expected performance value of the customer.

Table 2 QFD matrix

\begin{tabular}{|c|c|c|c|c|c|c|c|}
\hline PD & weight & $\mathbf{E}_{1}$ & $\mathbf{E}_{2}$ & $\mathbf{E}_{3}$ & $\ldots$ & $\mathbf{E}_{\mathbf{k}}$ & $v_{\mathrm{p}}$ \\
\hline $\mathbf{P}_{1}$ & $\mathrm{w}_{\mathrm{p} 1}$ & & & & & & \\
\hline $\mathbf{P}_{2}$ & $\mathrm{w}_{\mathrm{p} 2}$ & & & & & & \\
\hline $\mathbf{P}_{3}$ & $\mathrm{w}_{\mathrm{p} 3}$ & & & & & & \\
\hline ... & $\ldots$ & & & & & & \\
\hline \multirow[t]{3}{*}{$\mathbf{P}_{\mathbf{j}}$} & $\mathrm{w}_{\mathrm{pj}}$ & & & & & & \\
\hline & $v$ & & & & & & \\
\hline & $\mathrm{R}$ & & & & & & \\
\hline
\end{tabular}

\subsection{Remanufacturing Process Prediction Model Based on BPNN}

After extracting the performance value of the used products, it is necessary to build the relationship between the performance and the remanufacturing process scheme, and develop a method for solving the remanufacturing process parameters. Therefore, this study proposes a remanufacturing process prediction model based on the inversion theory, firstly, the mathematical models between performance and the remanufacturing process scheme are established, then, BPNN is used to predict the remanufacturing process scheme based on the performance demand.

\subsubsection{Mathematical model establishment between performance and remanufacturing process}

The goal of the remanufacturing process is to obtain products that meet the performance demand. Therefore, in the mathematical model, the performance demand is the objective function, and the remanufacturing process is a functional variable. It is a reverse process to solve the remanufacturing process parameters according to the product performance, so we can use the inversion theory to establish the relationship between the product performance and remanufacturing process parameters. It is assumed that the design variables contain the remanufacturing repair process $P r$, remanufacturing upgrading process $P u$, the origin performance $O P$ and the upgrade performance $U P$. It is assumed that an accurate forward model of the process design, which is expressed as follows:

$$
U^{\text {expect }}=f(P)
$$


Where $U^{\text {expect }}=\left\{u_{e 1}, u_{e 2}, \ldots, u_{e n}\right\}$ is the performance target vectors, which is the performance that the customers or designers expect the product to have, $P=\left\{p_{1}, p_{2}, \ldots, p_{n}\right\}$ is the processing technology that can achieve the performance targets. $f$ represents the functional relationship between the performance targets and the process parameters.

However, the original performance value of the used product is known, and upgrade performance value can be obtained based on the customer demand analysis, we need to select the suitable remanufacturing process scheme for performance recovery or performance upgrade. Thus, remanufacturing process solution based on product performance is a reverse remanufacturing process design process, which can be described as follows:

$$
\begin{gathered}
P_{r}=f_{1}\left(U_{o}^{\text {actual }}, F\right) \\
P_{u}=f_{2}\left(U_{d}^{a c t u a l}, F\right)
\end{gathered}
$$

Where $U_{o}^{\text {actual }}$ and $U_{d}^{\text {actual }}$ are the actual original performance and upgrade performance. $F=\left\{F_{1}, F_{2}, \ldots, F_{n}\right\}$ represents the failure features of the used products, which is the constraint of selecting remanufacturing process. $P_{r}$ and $P_{u}$ are the remanufacturing processes that can achieve the performance demand. Otherwise, the remanufacturing process needs to meet the constraint scope which contains the remanufacturing cost, time, and the environmental indicators, etc., which are expressed as follow:

$$
\begin{gathered}
P_{r}=\left\{p_{r 1}, p_{r 2}, \cdots, p_{r}\right\}, P_{r} \in D_{1}, D_{2}, D_{3} \\
P_{u}=\left\{p_{u 1}, p_{u 2}, \cdots, p_{u n}\right\}, P_{u} \in D_{1}, D_{2}, D_{3}
\end{gathered}
$$

Where $D_{1}$ represents the range of remanufacturing costs, $D_{2}$ represents the range of remanufacturing time, $D_{3}$ represents the environmental indicators.

\subsubsection{The establishment of the prediction model}

Back Propagation Neural Network (BPNN) is an intelligent algorithm that can build the mapping relationship between performance and remanufacturing process based on the historical remanufacturing data. BPNN contains the input layer, hidden layer and output layer, input layer contains the performance demand data and failure feature data. The hidden layer is the internal information processing layer, which response to information transformation, the output layer is the output of the remanufacturing process scheme, the BPNN can be constructed as Fig. 2.

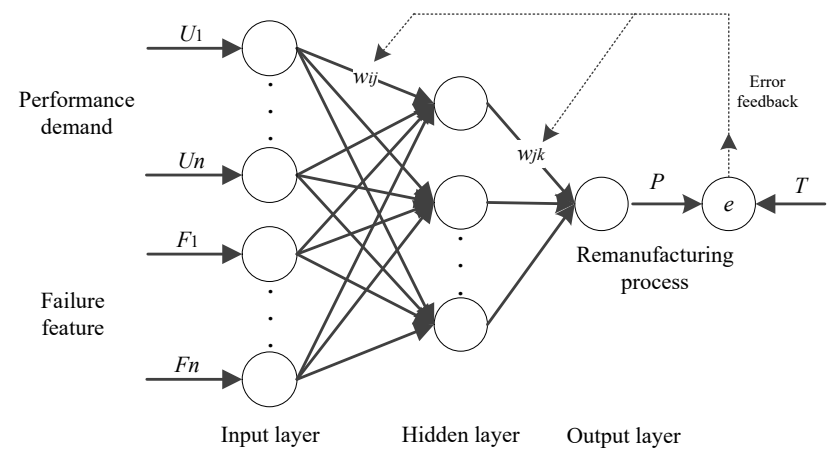


Fig.2. The structure of BPNN

In Fig.2. $U_{n}$ represents the $n$-th performance demand, $F_{n}$ represents the $n$-th failure feature, $w_{i j}$ represents the connection weight between the input layer and the hidden layer, $w_{j k}$ represents the connection weight between the output layer and the hidden layer, $P$ represents the predictive value of remanufacturing process scheme, $T$ represents the actual value of remanufacturing process scheme, $e$ represents the error between predictive value and actual value, the error can be feedback to the connection weights, and the connection weights will be adjusted based on the error until the error reaches the expected value.

BPNN can feedback the error of the output result to each connection weight until the prediction error reaches the desired value, which can improve the remanufacturing process prediction accuracy, the specific algorithm process is as follows.

Step 1: Network initialization. Each connection weight is assigned a random number in the interval ($1,1)$, and the error function value $e$, calculation accuracy value $\varepsilon$ and maximum learning times $M$ are set.

Step 2: Input and output layer design. The number of the nodes in the input layer is determined based on the performance demand and the number of failure features, the performance is the main remanufacturing targets, and the failure features are the constraint targets. The node of the output layer is 1 , which is the remanufacturing process scheme. Meanwhile, the performance demand value and failure feature value need to be normalized in $(0,1)$, the conversion process is as follows.

$$
y=2 *(x-\min x) /(\max x-\min x)-1
$$

Where $y$ is the value after normalization, $x$ is the input value.

Step 3: Hidden layer design. The number of hidden layer nodes is an important factor in fitting the nonlinear relationship function, which can be determined by Eq. (6).

$$
l=\sqrt{n+m}+a
$$

Where $l$ is the node number of the hidden layer, $n$ represents the node number of the input layer, $m$ represents the node number of the output layer, $a$ is a constant which is in $[1,10]$. The calculation process of the hidden layer input and output is as Eq. (7).

$$
\begin{array}{r}
H_{j}=f\left(\sum_{i=1}^{n} w_{i j} x_{i}-a_{j}\right) \\
P_{k}=\sum_{j=1}^{l} w_{j k} H_{j}+b_{k}
\end{array}
$$

Where $f$ is the activation function of the hidden layer, $a_{j}$ is the initialization threshold of the hidden layer, $b_{k}$ the threshold of the output layer. $H_{j}$ represents the output of the hidden layer, $P_{k}$ is the prediction value of the output layer.

Step 4: Predictive model parameters selection. The sigmoid function is used as the incentive function of the network, the tangent function (tansig) is used as the activation function of the hidden layer, the logarithmic function (logsig) is used as the excitation function of the output layer. The expressions of the three functions are as follows.

$$
f_{1}(x)=\frac{1}{1+e^{-\beta x}}, \beta>0
$$




$$
\begin{gathered}
f_{2}(x)=\frac{2}{1+\exp (-2 * n)}-1 \\
f_{3}(x)=\frac{1}{1+e^{-n e t}}
\end{gathered}
$$

Step 5: Network prediction error is calculated as Eq. (11).

$$
E=\frac{1}{2} \sum_{k=1}^{n}\left(T_{k}-P_{k}\right)
$$

Where $E$ is the total network prediction error, $T_{k}$ is the actual value of the output layer. Supposing that $e$ represents the error value between the actual value and the predictive value of the output, which is expressed by Eq. (12).

$$
e_{k}=T_{k}-P_{k}
$$

Then the total network error can be simplified as Eq. (13).

$$
E=\frac{1}{2} \sum_{k=1}^{n} e_{k}
$$

Step 6: Adjust the weights of the BPNN. The update formula for the connection weights from the hidden layer to the output layer is as Eq. (14).

$$
w_{j k}=w_{j k}+\eta H_{j} e_{k}
$$

Where $\eta$ represents the learning rate of the network.

The update formula for the connection weights from the input layer to the hidden layer is as Eq. (15).

$$
w_{i j}^{\prime}=w_{i j}+\eta H_{j}\left(1-H_{j}\right) x_{i} \sum_{k=1}^{m} w_{j k} e_{k}
$$

Step 7: Judge whether the network error value meets the set expected error value, if it is satisfied, output the remanufacturing scheme, if not, then return to the third step and enter step 3 until the network error reaches the expected value.

\section{Remanufacturing process scheme optimization}

\subsection{Conflicts identify based on TOC theory}

In the previous chapter, the remanufacturing process scheme can be obtained based on BPNN, however, due to the errors in prediction accuracy and differences in the working conditions, the remanufacturing process scheme will produce conflicts during the implementation process. To address that, the current reality tree (CRT) and contradiction resolution diagram (CRD) of TOC theory are used to determine the problems in remanufacturing process scheme, and establish the solution model respectively. Firstly, CRT is used to describe the actual situation of remanufacturing process design, and identify the core problems of the remanufacturing scheme, which is described in Fig.3. 


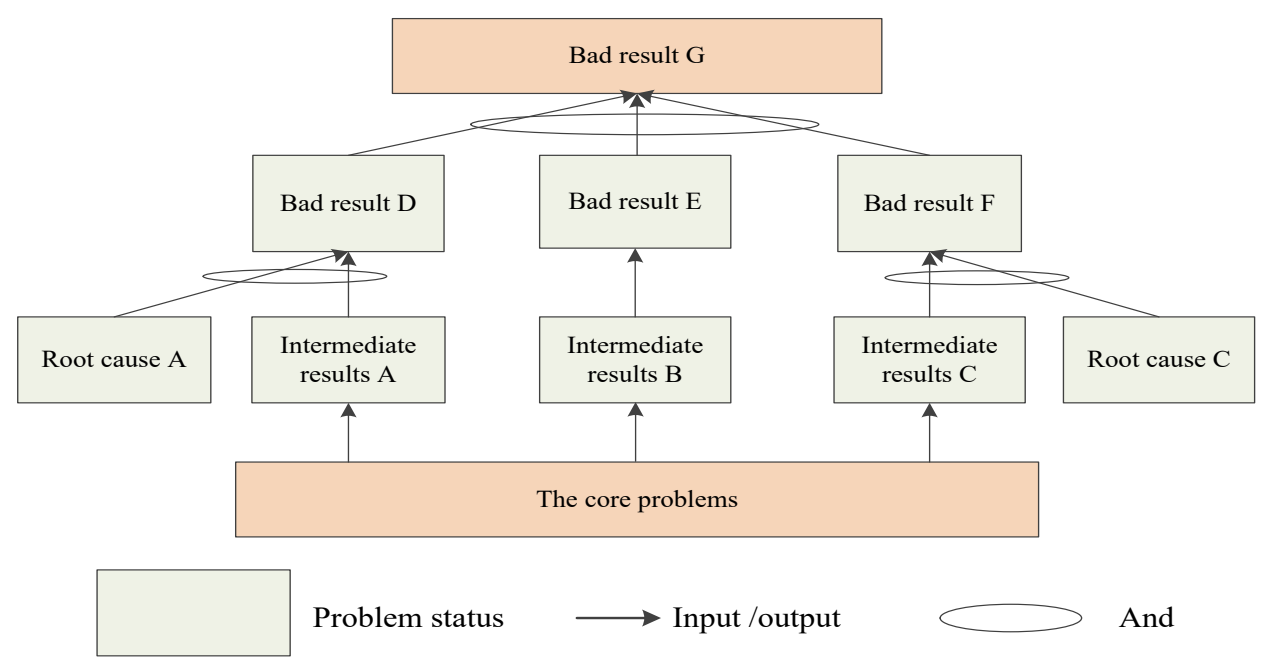

Fig.3. Current reality tree structure diagram of the remanufacturing process

CRT is used to describe the actual situation of a given system, which can reflect the causal relationship chain of the given system in certain specific environments, infer the root cause from the bad results of the system and determine the core problem. In the CRT, the core problems of the system should be determined, then the factors that caused the problem are determined, and the root causes of the problem are analyzed. Finally, the bad results caused are analyzed by the problem according to the influencing factors and root causes. After identifying the problems of the system, the main conflicts are determined by using CRD, which is described in Fig.4.

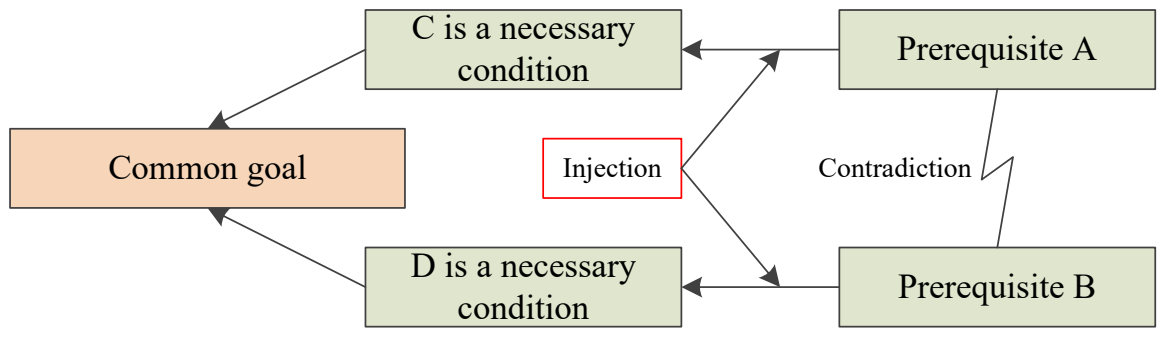

Fig.4. Contradiction resolution diagram construction mode

As shown in Fig.4, A and B are prerequisites for achieving the goal, but A and B are contradictory problems. If $A$ and $B$ exist at the same time, the goal cannot be achieved. After the CRD design system combing, what needs to be improved is clarified, and conflicts are found out in the remanufacturing process scheme. However, CBD is impossible to provide an effective solution, it is necessary to apply TRIZ theory to effectively solve the conflicts.

\subsection{Conflicts resolution based on TRIZ}

TRIZ is a systematic tool that can assist in solving problems and recommending inventive and effective solutions [29]. For establishing the relationship between feature parameter and TRIZ, each feature parameter of DFPR is mapped with the engineering parameter of the conflict matrix. The design features of the remanufacturing process are shown in Table 3. 
Table 3 Characteristics of remanufacturing process design

\begin{tabular}{|c|c|c|}
\hline & Design feature & Feature description \\
\hline \multirow{3}{*}{$\begin{array}{c}\text { Size } \\
\text { parameters(M) }\end{array}$} & Geometry size $\left(\mathrm{m}_{1}\right)$ & Size of each component \\
\hline & Shape $\left(m_{2}\right)$ & Appearance shape of each component \\
\hline & Dimensional tolerance $\left(\mathrm{m}_{3}\right)$ & Material type of each component \\
\hline \multirow{3}{*}{$\begin{array}{c}\text { Process } \\
\text { scheme }(\mathrm{P})\end{array}$} & Heat treatment process $\left(\mathrm{p}_{1}\right)$ & Acquiring Performance Requirements \\
\hline & Assembly process $\left(\mathrm{p}_{2}\right)$ & Reasonable assembly process \\
\hline & Machining process $\left(\mathrm{p}_{3}\right)$ & Process method for obtaining part size \\
\hline \multirow{3}{*}{$\begin{array}{c}\text { Performance } \\
\text { parameter (SP) }\end{array}$} & Hardness $\left(\mathrm{sp}_{1}\right)$ & $\begin{array}{l}\text { The ability to resist hard objects pressing into } \\
\text { its surface }\end{array}$ \\
\hline & Tensile strength $\left(\mathrm{sp}_{2}\right)$ & $\begin{array}{c}\text { Maximum Bearing Capacity of Parts under } \\
\text { Tensile Conditions }\end{array}$ \\
\hline & Bending strength $\left(\mathrm{sp}_{3}\right)$ & The ability of a material to resist bending \\
\hline \multirow{3}{*}{$\begin{array}{l}\text { Technical } \\
\text { solution(T) }\end{array}$} & Additive technolog $\left(\mathrm{t}_{1}\right)$ & Parts for rapid prototyping \\
\hline & Brush plating technology $\left(\mathrm{t}_{2}\right)$ & Remanufacturing of workpiece surface \\
\hline & Depositwelding technology $\left(\mathrm{t}_{3}\right)$ & Enhancing metal surface property \\
\hline
\end{tabular}

There are 39 standard parameters in TRIZ theory, which is shown in Table 4, each technical conflict can be represented by a pair of standard parameters. For each pair of standard parameters, the corresponding technical conflict can be solved by the 40 principles of invention and innovation, which are shown in Table 5 . The problem can be solved only by mapping the feature parameters to the standard parameters in TRIZ theory.

Table 4 The 39 standard parameters of TRIZ

\begin{tabular}{|c|c|c|c|}
\hline \multicolumn{4}{|c|}{39 standard parameters of TRIZ } \\
\hline $\begin{array}{c}\text { No.1 the weight of the } \\
\text { moving object }\end{array}$ & No.11 stress or pressure & No.21 power & $\begin{array}{c}\text { No.31 harmful factors } \\
\text { produced by objects }\end{array}$ \\
\hline $\begin{array}{l}\text { No.2 the weight of the } \\
\text { stationary object }\end{array}$ & No.12 shape & No.22 loss of capacity & No.32 manufacturability \\
\hline $\begin{array}{c}\text { No.3 the length of the } \\
\text { moving object }\end{array}$ & No.13 structural stability & No.23 Material loss & No.33 operability \\
\hline $\begin{array}{l}\text { No.4 the length of the } \\
\text { stationary object }\end{array}$ & No.14 strength & No.24 information loss & No.34 maintainability \\
\hline $\begin{array}{l}\text { No. } 5 \text { the area of the moving } \\
\text { object }\end{array}$ & $\begin{array}{l}\text { No.15 movement time of } \\
\text { moving objects }\end{array}$ & No. 25 time loss & $\begin{array}{c}\text { No.35 applicability and } \\
\text { versatility }\end{array}$ \\
\hline
\end{tabular}




\begin{tabular}{|c|c|c|c|}
\hline $\begin{array}{l}\text { No.6 the area of the } \\
\text { stationary object }\end{array}$ & $\begin{array}{l}\text { No.16 action time of } \\
\text { stationary objects }\end{array}$ & $\begin{array}{c}\text { No.26 quantity of matter or } \\
\text { thing }\end{array}$ & $\begin{array}{l}\text { No.36 complexity of the } \\
\text { device }\end{array}$ \\
\hline $\begin{array}{c}\text { No.7 the volume of the } \\
\text { moving object }\end{array}$ & No. 17 temperature & No.27 reliability & $\begin{array}{l}\text { No.37 difficulty of } \\
\text { monitoring and testing }\end{array}$ \\
\hline $\begin{array}{c}\text { No.8 the volume of the } \\
\text { stationary object }\end{array}$ & No.18 brightness & No.28 test accuracy & No.38 degree of automation \\
\hline No.9 velocity & $\begin{array}{l}\text { No.19 energy of moving } \\
\text { objects }\end{array}$ & $\begin{array}{l}\text { No.29 manufacturing } \\
\text { accuracy }\end{array}$ & productivity \\
\hline No.10 force & $\begin{array}{l}\text { No.20 energy of stationary } \\
\text { objects }\end{array}$ & $\begin{array}{l}\text { No.30 sensitivity to the } \\
\text { effects of harmful external } \\
\text { factors }\end{array}$ & \\
\hline
\end{tabular}

Table 5 The 40 principles of invention and innovation

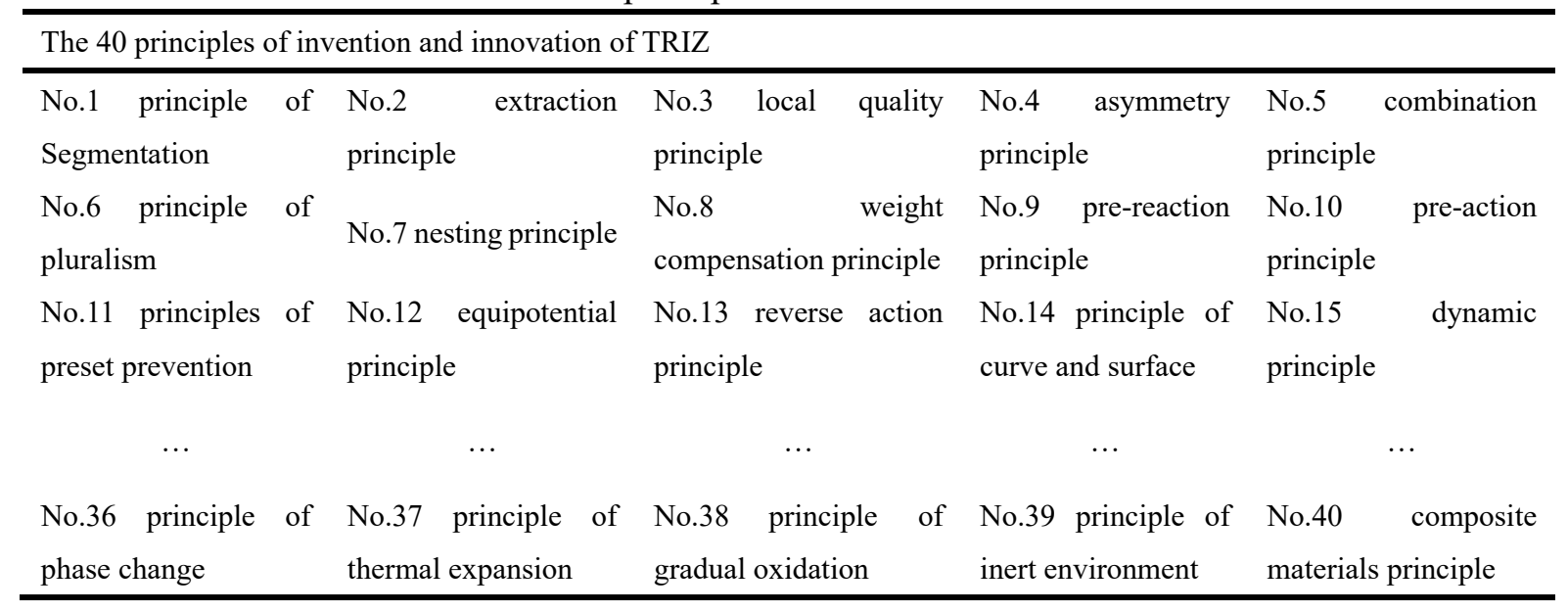

The process parameters can be described by the set of feature parameters of the design process:

$$
P L=\{M, P, S P, T\}
$$

where $P L$ represents the set of feature parameters, $P L$ is composed of sub-parameter which belong to size parameter, process scheme, performance parameter and technical solution.

Standard parameters in TRIZ theory are represented by sets:

$$
T R=\left\{A M_{1}, \ldots, A M_{i}, \ldots, A M_{39}\right\}
$$

Where $T R$ represents the standard parameter set in TRIZ theory, $A M_{i}$ indicates standard parameters. Then the mapping relationship between $P L$ and $T R$ is established, and each $P L$ parameter has a corresponding $T R$ parameter, the feature parameters can be found the suitable standard parameters based on TRIZ, the mapping relationship is expressed as follow:

$$
T R=f(P L)
$$

$f$ denotes the mapping relationship between $T R$ and $P L$, the parameters in $T R$ set represent the image of parameters in $P L$ set, the elements in $P L$ set are called the object of elements in $T R$ set about $f$. Each technical conflict consists of a pair of feature parameters, which can be represented by a pair of standard parameters in TRIZ, the description is as follow: 


$$
C T_{i j}=\left\{A M_{i}, A M_{j}\right\}
$$

$C T_{i j}$ represents the conflict in DFRP, $i$ and $j$ represent the serial numbers of any two in the thirty-nine standard parameters.

After mapping the technical conflicts to the TRIZ standard parameters, the solutions of conflicts can be found by referring to the conflict resolution matrix, which is shown in Table 6 . The solutions are usually heuristic results, and the designer can optimize the remanufacturing process scheme based on the solution, and generate a suitable remanufacturing process scheme, which can promote the smooth implementation of remanufacturing of the used product.

Table 6 The conflict resolution matrix

\begin{tabular}{|c|c|c|c|c|c|c|c|c|c|}
\hline & DEP & 1 & 2 & 3 & 4 & $\ldots$ & 37 & 38 & 39 \\
\hline IEP & & $A M_{1}$ & $A M_{2}$ & $A M_{3}$ & $A M_{4}$ & $\ldots$ & $A M_{37}$ & $A M_{38}$ & $A M_{39}$ \\
\hline 1 & $A M_{1}$ & & & $15,8,29,34$ & & & $28,29,26,32$ & $26,35,18,19$ & $35,3,24,37$ \\
\hline 2 & $A M_{2}$ & & & & $10,1,29,35$ & & $25,28,17,15$ & $2,26,35$ & $1,28,15,35$ \\
\hline 3 & $A M_{3}$ & $8,15,29,34$ & & & & & $35,1,26,24$ & $17,24,26,16$ & $14,4,28,29$ \\
\hline 4 & $A M_{4}$ & & $35,28,40,29$ & & & & 26 & & $30,14,7,26$ \\
\hline$\ldots$ & $\ldots$ & $\ldots$ & $\ldots$ & $\ldots$ & $\ldots$ & $\ldots$ & $\ldots$ & $\ldots$ & $\ldots$ \\
\hline 37 & $A M_{37}$ & $27,26,28,13$ & $6,13,28,1$ & $16,17,26,24$ & 26 & & & 34,21 & 35,18 \\
\hline 38 & $A M_{38}$ & $28,26,18,35$ & $28,26,35,10$ & $14,13,17,28$ & 23 & & $34,27,25$ & & $5,12,35,26$ \\
\hline 39 & $A M_{39}$ & $35,26,24,37$ & $28,27,15,3$ & $18,4,28,38$ & $30,7,14,26$ & & $35,18,27,2$ & $5,12,35,26$ & \\
\hline
\end{tabular}

\section{Case study}

This study takes the guide rail as an example to verify the feasibility of the remanufacturing process design method. A guide rail is an important part of the machine tool, but it is easy to wear during machining, which influences the precision, size, strength, etc. Therefore, it is necessary to design a suitable remanufacturing process scheme for the used guide rail, which can restore the performance of the guide rail to the new one or even surpass the new one.

In this case, 100 pieces of remanufacturing process data have been collected from the remanufacturer, and 50 pieces of performance demand data are collected by using the Likert scale, which mainly contain hardness improvement, flatness recovery, smooth guide rail surface, steady guide rail stiffness and size error, the demand information is described as Table 7.

Table 7 The performance demand data collection of the guide rail

\begin{tabular}{|c|c|c|c|c|c|c|c|}
\hline \multirow{2}{*}{ Number } & \multirow{2}{*}{ Object } & \multirow{2}{*}{ Perceptual evaluation } & \multicolumn{5}{|c|}{ Demand intensity } \\
\hline & & & 1 & 2 & 3 & 4 & 5 \\
\hline 1 & $\begin{array}{l}\text { Guiderail } \\
\text { surface }\end{array}$ & Smooth & & $\sqrt{ }$ & & & \\
\hline 2 & $\begin{array}{l}\text { Surface } \\
\text { hardness }\end{array}$ & Hard & & & & $\sqrt{ }$ & \\
\hline 3 & $\begin{array}{l}\text { Guide rail } \\
\text { straightness }\end{array}$ & Upright & & & & $\sqrt{ }$ & \\
\hline 4 & $\begin{array}{l}\text { Guiderail } \\
\text { Stiffness }\end{array}$ & Steady & & $\sqrt{ }$ & & & \\
\hline 5 & Size error & Small & & & $\sqrt{ }$ & & \\
\hline
\end{tabular}

For accurately extracting the performance demand targets, the performance demand is mapped to 
product features by using QFD, the weights are determined according to the proportion of the demand data, which can be expressed by Table 8 .

Table 8 Engineering feature mapping by QFD

\begin{tabular}{lclllll}
\hline $\mathbf{P D}$ & weight & $\mathbf{E}_{\mathbf{1}}$ & $\mathbf{E}_{\mathbf{2}}$ & $\mathbf{E}_{\mathbf{3}}$ & $\mathbf{E}_{\mathbf{4}}$ & $\mathbf{E}_{\mathbf{5}}$ \\
\hline $\mathbf{P}_{\mathbf{1}}$ & 0.16 & 3 & 0 & 1 & 0 & 1 \\
$\mathbf{P}_{\mathbf{2}}$ & 0.34 & 0 & 3 & 0 & 2 & 0 \\
$\mathbf{P}_{\mathbf{3}}$ & 0.32 & 1 & 0 & 3 & 0 & 1 \\
$\mathbf{P}_{\mathbf{4}}$ & 0.08 & 0 & 2 & 0 & 3 & 0 \\
$\mathbf{P}_{\mathbf{5}}$ & 0.10 & 1 & 0 & 1 & 0 & 3 \\
& $v$ & 0.9 & 1.18 & 1.22 & 0.92 & 0.78 \\
& $\mathrm{R}$ & 4 & 2 & 1 & 3 & 5 \\
\hline
\end{tabular}

In Table 8, four engineering features are determined by the technician analysis, which are listed as follows.

(E $E_{1}$ surface finish $\leq \mathrm{Ra} 0.5 \mu \mathrm{m}$.

$\left(\mathrm{E}_{2}\right)$ surface hardness $\geq 60 \mathrm{HRC}$.

(E3) straightness $\leq 0.10 / 1000 \mathrm{~mm}$.

(E4) stiffness $\geq 8000 \mathrm{~N} / \mu \mathrm{m}$.

$\left(\mathrm{E}_{5}\right)$ size error $\leq 0.02 \mathrm{~mm}$.

By calculating the absolute weight value of the engineering feature, the importance ranking of the engineering feature is obtained, therefore, according to the performance demand, the first four engineering features are determined as the remanufacturing targets. Otherwise, in this case, the failure features of the guide rail are wear $\left(\mathrm{F}_{5}\right)$ and $\operatorname{crack}\left(\mathrm{F}_{6}\right)$, the corresponding value are $5.5 \mathrm{~mm}$ and $3.1 \mathrm{~mm}$.

Then, the BPNN needs to be trained based on the remanufacturing process data. Finish, hardness, straightness, and stiffness of the guide rail are used as the input parameters in the BPNN, and the remanufacturing process scheme is the output data. Firstly, 100 pieces of remanufacturing process data are divided into training data sets and test data, the first 80 sets of data are used to train BPNN, and the remaining 20 sets of data are used for testing the predictive model, the data classification is shown as Table 9, and the 50 corresponding remanufacturing schemes are shown in Table 10.

Table 9 Remanufacturing process data classification

\begin{tabular}{|c|c|c|c|c|c|c|c|c|c|}
\hline \multirow{3}{*}{$\begin{array}{l}\text { Serial } \\
\text { number }\end{array}$} & \multicolumn{4}{|c|}{ Performance demand } & \multicolumn{4}{|c|}{ Failure feature } & \multirow{3}{*}{$\begin{array}{c}\text { Scheme } \\
\text { Serial } \\
\text { number }\end{array}$} \\
\hline & $\begin{array}{l}\text { Finish } \\
(\mu \mathrm{m})\end{array}$ & $\begin{array}{l}\text { Hardness } \\
\text { (HRC) }\end{array}$ & $\begin{array}{c}\text { Straightness } \\
(\mathrm{mm})\end{array}$ & $\begin{array}{l}\text { Stiffness } \\
(\mathrm{N} / \mu \mathrm{m})\end{array}$ & $\begin{array}{l}\text { Wear } \\
(\mathrm{mm})\end{array}$ & $\begin{array}{l}\text { Creep } \\
\left(\mathrm{mm}^{2}\right)\end{array}$ & $\begin{array}{l}\text { Crack } \\
(\mathrm{mm})\end{array}$ & $\begin{array}{c}\text { Deformation } \\
\left(^{\circ}\right)\end{array}$ & \\
\hline & $\mathrm{U}_{1}$ & $\mathrm{U}_{2}$ & $\mathrm{U}_{3}$ & $\mathrm{U}_{4}$ & $\mathrm{~F}_{1}$ & $\mathrm{~F}_{2}$ & $\mathrm{~F}_{3}$ & $\mathrm{~F}_{4}$ & \\
\hline 1 & 0.6 & 55 & 0.11 & 7500 & 4.1 & 1.2 & 2.5 & 2.4 & 1 \\
\hline 2 & 0.5 & 56 & 0.10 & 7800 & 5.6 & 1.5 & 3.2 & 2.7 & 8 \\
\hline
\end{tabular}




\begin{tabular}{cccccccccc}
\hline 3 & 0.6 & 55 & 0.11 & 7500 & 4.1 & 1.2 & 2.5 & 2.4 & 15 \\
$\ldots$ & $\ldots$ & $\ldots$ & $\ldots$ & $\ldots$ & $\ldots$ & $\ldots$ & $\ldots$ & $\ldots$ & $\ldots$ \\
99 & 0.6 & 55 & 0.11 & 7500 & 4.1 & 1.2 & 2.5 & 2.4 & 48 \\
100 & 0.6 & 55 & 0.11 & 7500 & 4.1 & 1.2 & 2.5 & 2.4 & 36 \\
\hline
\end{tabular}

Table 10 Remanufacturing process scheme

\begin{tabular}{cc}
\hline Serial number & Remanufacturing process scheme \\
\hline 1 & Heating- straighter- annealing \\
2 & Laser cladding- turning- grinding \\
3 & Arc spraying- turning- grinding- fine grinding \\
$\ldots$ & $\ldots$ \\
49 & Electroplating brush- surfacing \\
50 & Plasma spraying-rough grinding- fine grinding \\
\hline
\end{tabular}

After determining the training samples and test samples, parameter values of BPNN need to be set. According to Eq. (7), the number of the hidden nodes are is 10, the number of the input nodes is 8 and the output node is 1 . Therefore, the BPNN model can be selected with an 8-10-1 structure containing a hidden layer. Besides, the number of network iterations $M$ is set to 5000, the expected error $\varepsilon$ is set to $10^{-2}$, the learning rate $\eta$ is set to 0.01 .

the number of training and the error value are shown in Fig.5. And the comparison between the actual output value and the predictive output value is shown in Fig. 6.

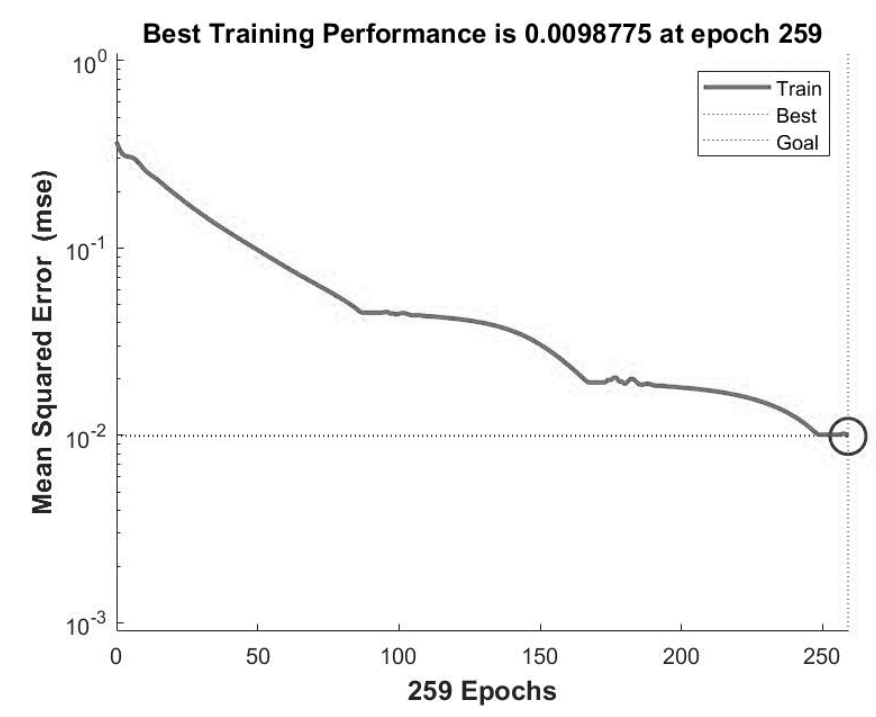

Fig.5. Error curve 


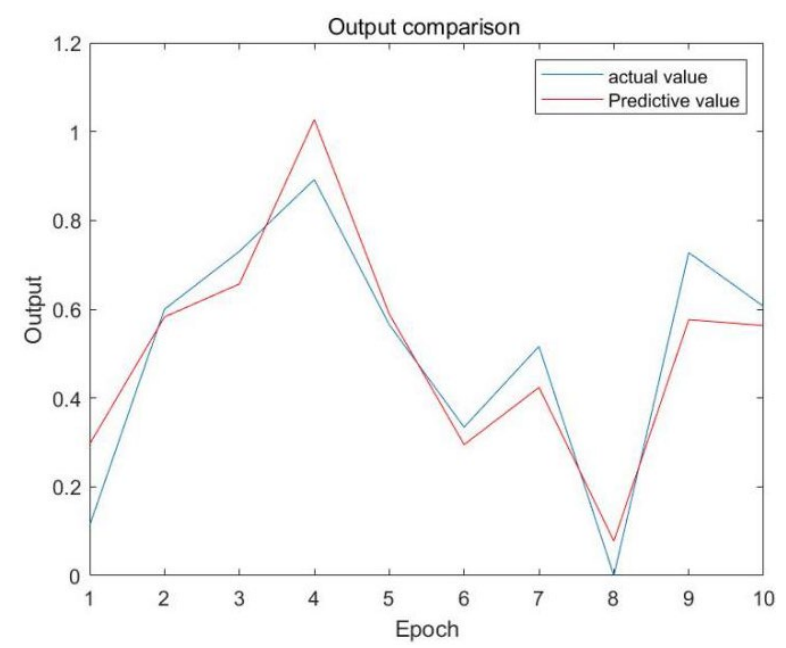

Fig.6. Comparison of actual output and predictive output

From Fig.5 and Fig.6. When the training reaches 259 steps, the error reaches $10^{-2}$, which meets the network setting requirements. For solving the remanufacturing process scheme that can meet the performance demand, $E_{1}, E_{2}, E_{3}, E_{4}$ are the performance demand input, $F_{5}$ and $F_{6}$ are the failure feature input, the remanufacturing process scheme 8 can be obtained which can meet the performance demand based on BPNN, the solution is shown in Fig.7.

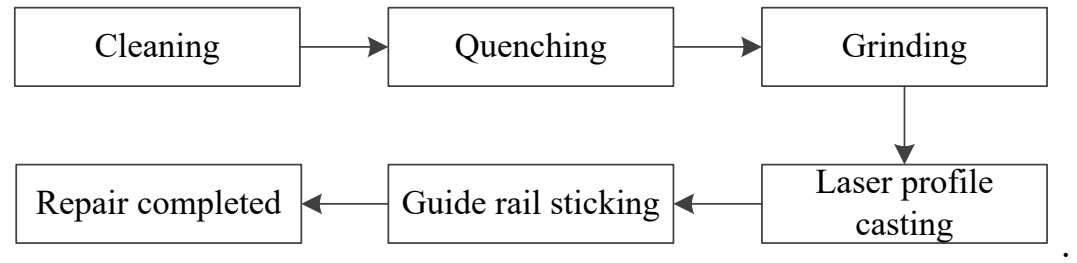

Fig.7. Remanufacturing process scheme

As shown in Fig.7. Quenching the failure guide rail can improve the hardness of the guide, then the surface grinding is carried out with the guide grinder. Finally, the laser repairing method is used to restore the damaged parts for the guideway. Although every remanufacturing process can restore performance for the product, there are conflicts in the implementation of the process. After grinding, the size of the guide decreases and it cannot be aligned with the center of the chuck, which will lead to errors in parts processing.

The key concept of TOC is to manage the constraint of the system, which can determine the conflicts of the remanufacturing process scheme. CRD and CRT are used to identify the core conflict and problem respectively. The current reality tree is used to sort out the remanufacturing process problems, as shown in Fig.8. 


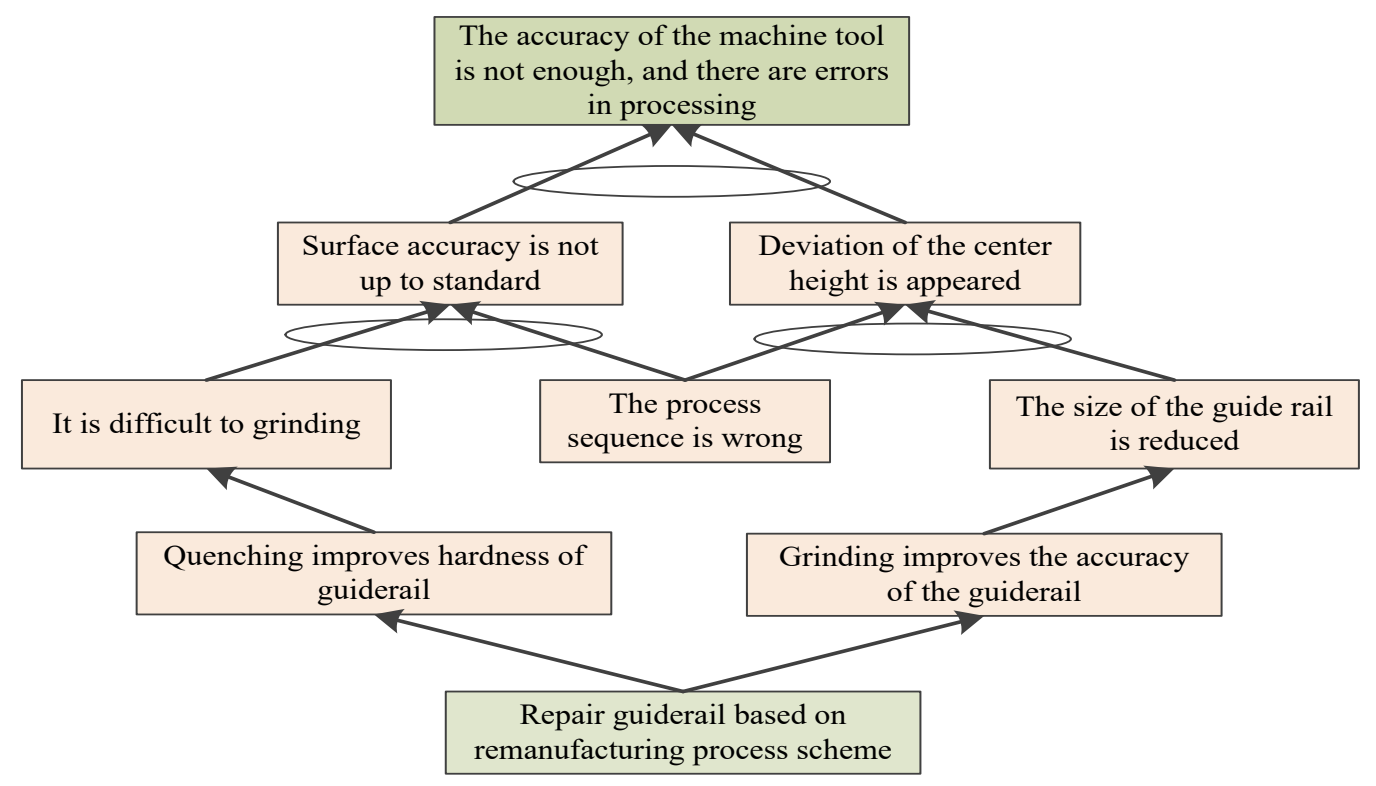

Fig.8. Using current reality tree to sort out the remanufacturing process problems

As shown in Fig.8, although quenching can improve the hardness of the guide rail, it is not conducive to grinding the guide rail to improve the surface accuracy. Meanwhile, grinding can improve the accuracy of the guide rail, but it will reduce the size of the guide rail, which cannot guarantee machining accuracy. Therefore, there are problems in the remanufacturing process scheme, and the core problems need to be determined and optimized

Conflict Resolution Diagram (CRD) is used to identify conflicts in remanufacturing process, as shown in Fig.9 and Fig.10.

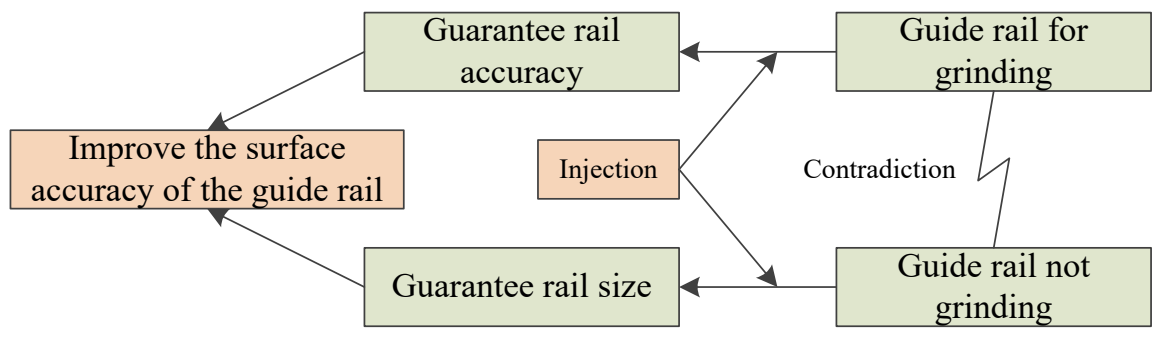

Fig.9. Conflict resolution diagram for improving the accuracy

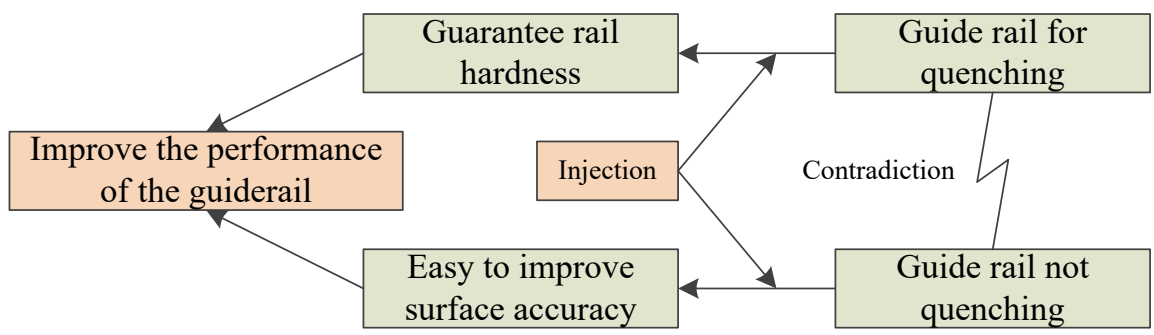

Fig.10. Conflict resolution diagram for improving the hardness

By constructing the CRD of the remanufacturing process scheme, the problems are sorted out and the contradictions in the process of guide rail remanufacturing process are determined. Grinding technology can improve the accuracy and surface roughness of the guide rail, but it will reduce the size of the guide rail, which is a pair of contradictions. Besides, quenching can improve the hardness of the guide rail, 
but it is not conducive to improving the surface accuracy of the guide rail, which is a pair of contradictions.

After determining the conflicts of the remanufacturing process scheme, TRIZ theory is used to solve the conflict. Firstly, for building the relationship between process problems and TRIZ, process problems need to be mapped to engineering parameters in the TRIZ conflict matrix. As accuracy and size is a pair conflict, accuracy of guide rail is associated with manufacturing accuracy, the size of guide rail is associated with the volume of the stationary object in TRIZ engineering parameters. Then the corresponding inventive principles are found according to the conflict matrix table, and the application process is shown in Table 11.

Table 11 Application process of the TRIZ

\begin{tabular}{ccc}
\hline \multicolumn{2}{c}{ Technical parameters of TRIZ } & Invention principle \\
\hline $\begin{array}{c}\text { Parameters that need to be } \\
\text { improved }\end{array}$ & 29-Manufacturing & 25-Self-service principle \\
& & 10-Preaction principle \\
Deteriorating parameters & 8-Volume of the & 35-Principle of changing physical or \\
& stationary object & chemical parameters \\
\hline
\end{tabular}

Finally, by analyzing the principles of each invention, the10-preaction principle can resolve process conflicts, that the laser casting is performed before griding, and the solutions are shown in Fig.11.

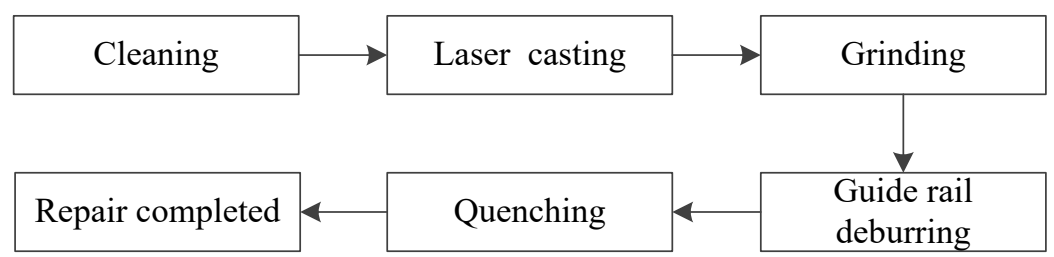

Fig.11. Improved remanufacturing process scheme

The repaired guide rail is shown in Fig.12.

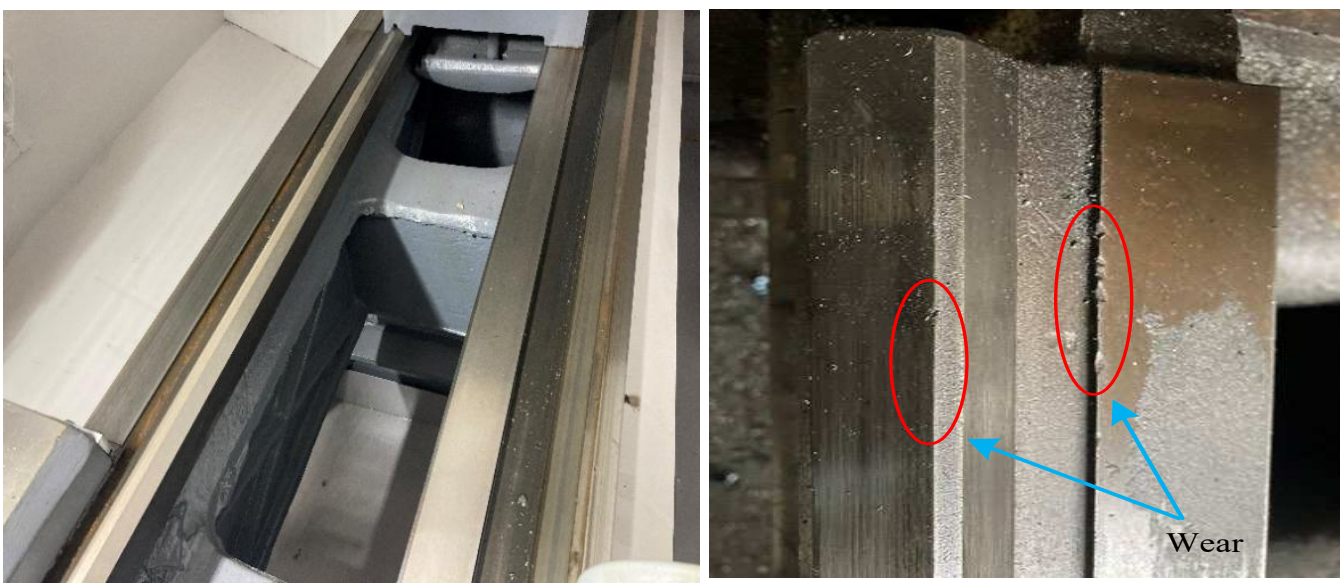

Fig.12. Guiderail after repaired and before repaired

This study aims to propose an integrated design method for remanufacturing process, which can rapidly generate the remanufacturing process scheme and satisfy the performance demand. It was found that the proposed method is feasible to generate the remanufacturing process scheme by reusing the historical remanufacturing process data, and resolve the conflicts of remanufacturing process scheme based on TOC and TRIZ theory. The specific remanufacturing process scheme is as follows. The guide 
rail of the lathe is wearing, which affects the machining accuracy, for improving machining accuracy and the performance of the guide rail, the guide rail is cleaned by diesel and wiped clean firstly. Then, laser casting is used to repair the worn part of the guide rail. After repairing, the grinder is used to grind the guide rail plane so that the surface roughness of the guide rail reaches Ra0.5um and the straightness reaches $0.08 / 1000 \mathrm{~mm}$, which can be detected by the three-coordinate measuring machine. The process sequence of laser casting and grinding should be placed in the right steps, if the grinding is in the front and the laser cladding is in the back, the roughness and flatness of the repaired part will not meet the demand. Meanwhile, the angle grinder is used to remove burrs on guide rails, finally, high-frequency quenching is used to enhance the hardness of the guide rail to $65 \mathrm{HRC}$, which can be detected by the hardness tester. Through remanufacturing process scheme prediction and conflict resolution, the optimal remanufacturing scheme can be obtained, the guide rail after remanufacturing is shown in Fig.11. It can be seen in Fig.11. the wear of the guide rail has been restored, and the surface of the guide rail has been smoother. Otherwise, in Fig.5. BPNN reached the error requirement in 1 second and output the remanufacturing process scheme, which greatly improved the efficiency of DFRP.

\section{Conclusions}

This study proposes an integrated design method for remanufacturing process based on performance demand, which could provide both theoretical and practical insights for generating and optimizing the remanufacturing process scheme. The main contributions could be concluded as follows: (1) Kansei Engineering and QFD are integrated to analyze the performance demand, which can accurately describe the demand and map the performance demand to the engineering features; (2) the predictive model based on BPNN is established which can reuse the historical remanufacturing process data to rapidly generate the remanufacturing process scheme, and the remanufacturing process scheme is more in line with performance demand; (3) TOC and TRIZ are applied to resolve the conflicts of the remanufacturing process scheme, under this method, the remanufacturing process scheme can be optimized and promote the smooth implementation of remanufacturing.

The future work requires efforts in the following aspects:

(1) TOC and TRIZ can resolve the conflicts of the remanufacturing process schemes, but they cannot intelligently provide solutions to conflicts, in future work, case-based reasoning, rule-based reasoning and k-Nearest Neighbor are applied to resolve the conflicts and make the solution process more intelligent; (2) remanufacturing process design software will be developed to make the design method more integrated, which contains performance demand analysis, remanufacturing process scheme generation and remanufacturing process scheme optimization.

Funding information This research paper is supported by the National Natural Science Foundation of China (Grant No. 52075396, Grant No. 51905392). These financial contributions are gratefully acknowledged.

\section{Declarations}

Ethical approval All procedures performed in studies involving human participants were in accordance with the ethical standards of the institutional and/or national research committee or comparable ethical standards.

Consent to participate Informed consent was obtained from all individual participants included in the study.

Consent to publish The participants provided informed consent for publication of their statements.

Disclaimer The use of the commercial software systems identified in this paper to assist the progress of design, development and understanding does not imply that such systems are necessarily the best available for the purpose. 
Conflict of interest No potential conflict of interest was reported by the authors and the stakeholders.

\section{References}

1. Cai, W. , Liu, F. , Dinolov, O. , Xie, J., Liu, P. , Tuo, J. (2018) Energy benchmarking rules in machining systems. Energy, 142(jan.1), 258-263. https://doi.org/10.1016/j.energy.2017.10.030

2. Jiang, Zhigang; Jiang, Ya; Wang, Yan; Zhang, Hua; Cao, Huajun; Tian, Guangdong (2016) A hybrid approach of rough set and case-based reasoning to remanufacturing process planning. $\mathrm{J}$ Intell Manuf. https://doi.org/10.1007/s10845-016-1231-0

3. Jiang, Zhigang; Fan, Zhou; Sutherland, John W.; Zhang, Hua; Zhang, Xugang (2014) Development of an optimal method for remanufacturing process plan selection. Int J Adv Manuf Technol, 72(9-12), 15511558. https://doi.org/10.1007/s00170-014-5783-X

4. Wang, H. , Jiang, Z., Zhang, X. , Wang, Y. , \& Wang, Y. . (2017). A fault feature characterization based method for remanufacturing process planning optimization. J CLEAN PROD, 708-719. https://doi.org/10.1016/j.jclepro.2017.05.178

5. Shakourloo, Ali (2016) A multi-objective stochastic goal programming model for more efficient remanufacturing process. Int J Adv Manuf Technol. https://doi.org/10.1007/s00170-016-9779-6

6. Li, Congbo; Tang, Ying; Li, Chengchuan; Li, Lingling (2013) A Modeling Approach to Analyze Variability of Remanufacturing Process Routing. IEEE T AUTOM SCI ENG, 10(1), 8698. https://doi.org/10.1109/tase.2012.2217330

7. Kin, S. Tsang Mang; Ong, S.K.; Nee, A.Y.C. (2014) Remanufacturing Process Planning. Procedia CIRP, 15(), 189-194. https://doi.org/10.1016/j.procir.2014.06.087

8. Zhang, Xugang; Zhang, Hua; Jiang, Zhigang; Wang, Yanhong (2015) An integrated model for remanufacturing process route decision. INT J COMPUT INTEG M, 28(5), 451459. https://doi.org/10.1080/0951192x.2014.880804

9. Cao, H. J., Wang, B. T. , F Liu, \& Jia-Qi, M. A. . (2010) Two-phase decision-making strategy for remanufacturing process planning. Computer Integrated Manufacturing Systems.

10. Mitsuo Nagamachi (2002) Kansei engineering as a powerful consumer-oriented technology for product development. APPL ERGON, 33(3), 289-294. https://doi.org/10.1016/s0003-6870(02)00019-4

11. Hartono, Markus (2020) The modified Kansei Engineering-based application for sustainable service design. INT J IND ERGONOM, 79, 102985. https://doi.org/10.1016/j.ergon.2020.102985

12. Jiao, Y R, Qu Q X (2019) A proposal for Kansei knowledge extraction method based on natural language processing technology and online product reviews. COMPUT IND, 108, 111. https://doi.org/10.1016/j.compind.2019.02.011

13. Yeh, Cheng-Ta; Chen, Mu-Chen (2018) Applying Kansei Engineering and data mining to design door-todoor delivery service. COMPUT IND ENG, 120, 401-417. https://doi.org/10.1016/j.cie.2018.05.011

14. Jacques Marsot (2005) QFD: a methodological tool for integration of ergonomics at the design stage. APPL ERGON, 36(2), 185-192. https://doi.org/10.1016/j.apergo.2004.10.005

15. Fang, Xinghua; Shen, Yixuan; Zhou, Jian; Pantelous, Athanasios A.; Zhao, Mingxuan (2020) QFD-Based Product Design for Multisegment Markets: A Fuzzy Chance-Constrained Programming Approach. IEEE T ENG MANAGE,1-15. https://doi.org/10.1109/TEM.2020.3009163

16. Sousa-Zomer, Thayla T.; Miguel, Paulo A. Cauchick (2016). A QFD-based approach to support sustainable product-service systems conceptual design. Int J Adv Manuf Technol. https://doi.org/10.1007/s00170-016$\underline{8809-8}$ 
17. Mistarihi, M. Z. , Okour, R. A. , \& Mumani, A. A. . (2020). An integration of a QFD model with fuzzy-ANP approach for determining the importance weights for engineering characteristics of the proposed wheelchair design. APPL SOFT COMPUT, 90, 106136. https://doi.org/10.1016/j.asoc.2020.106136

18. HUYNH, Nhat-To (2020) Online defect prognostic model for textile manufacturing. RESOUR CONSERV RECY, 161(), 104910. https://doi.org/10.1016/j.resconrec.2020.104910

19. Chang, Yushuo; Yue, Jianfeng; Guo, Rui; Liu, Wenji; Li, Liangyu (2020) Penetration quality prediction of asymmetrical fillet root welding based on optimized BP neural network. J MANUF PROCESS, 50(), 247254. https://doi.org/10.1016/j.jmapro.2019.12.022

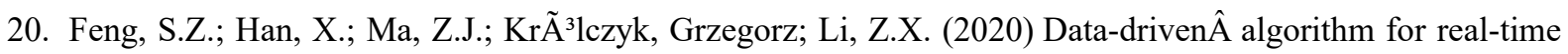
fatigue life prediction of structures with stochasticÂ parameters. COMPUT METHOD APPL M, 372(), 113373. https://doi.org/10.1016/j.cma.2020.113373

21. Kwon, He-Boong (2017) Exploring the predictive potential of artificial neural networks in conjunction with DEA in railroad performance modeling. Int. J. Production Economics, 183(), 159170. https://doi.org/10.1016/j.ijpe.2016.10.022

22. Shao hua, Cui; Jiang-ping, Mei; Ling-hua, Zhang; Xiao, Du (2017) Based on the Theory of TRIZ Solving the Problem of 18650 Battery Electrolyte Filling. IOP Conference Series: Earth and Environmental Science, 104, 012018. https://doi.org/10.1088/1755-1315/104/1/012018

23. Hsieh, Ho-Nien; Chen, Jeng-Fung; Do, Quang Hung (2017) A creative research based on DANP and TRIZ for an innovative cover shape design of machine tools. J ENG DESIGN, 28(2), 7799. https://doi.org/10.1080/09544828.2016.1272100

24. Bao, H. , Liu, Z. , D Hu, Ke, Q., Zhang, C. . (2016). Research on green innovation design method of active manufacturing using TRIZ. Journal of Mechanical Engineering, 52(5), 33-39. https:// doi.org/10.3901/JME.2016.05.033

25. Kendall, G. I. . (2010). Securing the future; strategies for exponential growth using the theory of constraints. AQUAC RES, 10(3), 129-132. https://doi.org/10.1111/j.1365-2109.1979.tb00264.x

26. Dettmer, H.W. (1997) Goldratt's theory of constraints: a systems approach to continuous improvement.

27. Bauer, J. M. , Vargas, A., Sellitto, M. A., Souza, M. C. , \& Vaccaro, G. L. . (2019). The thinking process of the theory of constraints applied to public healthcare. Business Process Management Journal. https://doi.org/ $\underline{\text { 10.1108/BPMJ-06-2016-0118 }}$

28. Huang, W., Hou, L., Zhao, N., \& Lin, W. G. (2012) Product innovation and evaluation based on TOC and TRIZ. Advanced Materials Research. https://doi.org/10.4028/www.scientific.net/AMR.421.709

29. Ishak N M,Sivakumar D,Mansor M R.The application of TRIZ on natural fibre metal laminate to reduce the weight of the car front hood[J]. J BRAZ SOC MECH SCI,2018,40(2):105. https://doi.org/10.1007/s40430$\underline{018-1039-2}$ 